\title{
Introduction to \\ Digital Filters
}


Also from The Macmillan Press

An Introduction to the Analysis and Processing of Signals

Paul A. Lynn

Analysis and Design of Sequential Digital Systems

L. F. Lind and J. C. C. Nelson

Digital Hardware Design

Ivor Catt, David Walton and Malcolm Davidson

Electrical Communications theory, worked examples and problems

R. G. Meadows

Modern Communication Systems

R. F. W. Coates

Transmission Lines for Communications

C. W. Davidson 


\section{Introduction to Digital Filters}

Trevor J. Terrell

Principal Lecturer,

Preston Polytechnic 
All rights reserved. No part of this publication may be reproduced or transmitted, in any form or by any means, without permission.

First published 1980 by

THE MACMILLAN PRESS LTD

London and Basingstoke

Associated companies in Delhi Dublin

Hong Kong Johannesburg Lagos Melbourne

New York Singapore and Tokyo

Typeset in 10/12 IBM Press Roman by

Reproduction Drawings Ltd, Sutton; Surrey

\section{British Library Cataloguing in Publication Data}

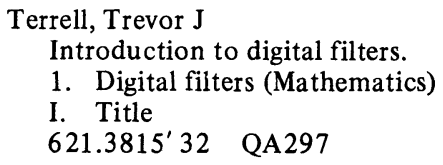

Terrell, Trevor J

Introduction to digital filters.

1. Digital filters (Mathematics)

I. Title

621.3815'32 QA297

ISBN 978-0-333-24671-9

DOI 10.1007/978-1-349-16313-7

ISBN 978-1-349-16313-7 (eBook)

This book is sold subject to the standard conditions of the Net Book Agreement.

The paperback edition of this book is sold subject to the condition that it shall not, by way of trade or otherwise, be lent, resold, hired out, or otherwise circulated without the publisher's prior consent in any form of binding or cover other than that in which it is published and without a similar condition including this condition being imposed on the subsequent purchaser. 
To Jennifer, Janet and Lesley 


\section{Contents}

Preface $\quad$ ix

1 Introduction 1

1.1 Background to Digital Filters 1

1.2 Sampled-data Signals 3

1.3 The $Z$-transform 6

1.4 Method of Determining $Z$-transforms from Laplace Transforms 21

1.5 The Inverse $Z$ - transform 23

1.6 The Digital Filter Transfer Function 26

1.7 The Discrete Fourier Transform 32

1.8 The Fast Fourier Transform 34

1.9 Concluding Remarks 37

2 Design of Recursive Digital Filters 40

2.1 Introduction 40

2.2 Indirect Approach using Prototype Continuous Filter 41

2.3 Frequency Sampling Filters 68

2.4 Direct Approach using Squared Magnitude Function 77

$\begin{array}{ll}2.5 & \text { Wave-shaping Filters } \\ \end{array}$

3 Design of Non-recursive Digital Filters 89

3.1 Introduction $\quad 89$

3.2 Frequency-domain Design using Window Functions 90

3.3 Equiripple Approximation Method 95

3.4 An Analytical Technique for Designing FIR Filters 100

3.5 Time-domain Design of the Digital Transversal Filter 109 
4 Quantisation Considerations in Digital Filter Implementation

4.1 Introduction 112

4.2 Binary Number Representations 113

4.3 Quantisation of the Digital Filter Input Signal 117

4.4 Realisation Structure Considerations 121

4.5 Limit Cycle Oscillations 139

4.6 Overflow Oscillations 143

4.7 Concluding Remarks 145

5 Practical Implementation of Digital Filters 148

$\begin{array}{lll}5.1 & \text { Introduction } & 148\end{array}$

5.2 Implementation using Dedicated Hardware 148

5.3 Implementation using Digital Computers 164

5.4 Signals and Noise 186

5.5 Concluding Remarks 193

$\begin{array}{ll}\text { Appendixes to Chapter } 5 & 194\end{array}$

$\begin{array}{ll}\text { Answers to Problems } & 212\end{array}$

$\begin{array}{ll}\text { Index } & 215\end{array}$ 


\section{Preface}

In the 1970s computer technology has progressed at a phenomenal rate and, as microprocessor systems continue to develop, the cost of implementing digital signal processors will, hopefully, correspondingly decrease. Consequently in the 1980s it is expected that the number of practical applications of digital filters will significantly increase; furthermore it is possible that many established continuous-time filter systems will be replaced by equivalent digital filter systems. There is therefore a growing need for more well-trained engineering and science graduates, postgraduates and practising engineers who are skilled in the design and implementation of digital filter systems. Fortunately many polytechnics and universities have already recognised the importance of digital signal processing, and this subject now generally forms part of the core material in many undergraduate and postgraduate engineering courses.

This book presents a concise introduction to the fundamental techniques involved in the design and implementation of digital filters. The level of the information presented makes it suitable for use mainly in the second and the final years of electrical and electronic engineering undergraduate courses. Some of the material goes beyond the undergraduate level and will be useful to postgraduate students and practising engineers. The book includes many appropriate worked examples which serve to illustrate theoretical concepts as they are developed in the text. Indeed, the main purpose of the worked examples is to help to bridge the gap between the theoretical and practical aspects of digital filters, and it is intended that this feature will greatly assist the reader (especially the undergraduate student) in relating the theory to practical results.

The first chapter introduces sampled-data signals and systems, and the basic required mathematical concepts of the $Z$-transform and the inverse $Z$-transform are developed. In chapter 2 a number of useful design methods applicable to recursive digital filters are described in detail. The design methods applicable to non-recursive digital filters are examined in chapter 3 . The main considerations that must be given to quantisation effects in the practical implementation of digital filters are discussed in chapter 4 . In chapter 5 (the final chapter) hardware and software aspects of digital filter implementation are discussed in detail, and 
some pertinent microprocessor system concepts are described. The appendixes at the end of the book have been included to help the reader who wishes to undertake the task of translating a 'paper design' into a practical working digital filter. Typically the latter may be a project for the undergraduate student, or indeed in some cases a postgraduate student, or project development undertaken by the practising engineer.

I wish to express my thanks to my colleague Dr R. J. Simpson (Preston Polytechnic) for his encouragement and helpful advice during the preparation and writing of this book. I also wish to express my thanks to Mr G. Collins (Preston Polytechnic) for his invaluable assistance in sorting out practical problems associated with software used in implementing some of the digital filter designs presented in the book. I gratefully thank Dr E. T. Powner (UMIST) and Dr M. G. Hartley (UMIST) for giving me the opportunity to teach some of the material in this book to postgraduate students on their M.Sc. Digital Electronics course. My thanks also go to Mrs T. Smith for her cheerfulness and competence in typing the manuscript. I especially thank my wife, Jennifer, for her love, patience, encouragement and understanding. 